\title{
O discurso sobre língua materna e língua nacional: traço de uma colonização linguística
}

The discourse on mother tongue and national language: trace of a linguistic colonization

\author{
Divino Alex Rocha-de-Deus ${ }^{1}$ \\ Universidade do Estado de Mato Grosso \\ Eliana de Almeida ${ }^{2}$ \\ Universidade do Estado de Mato Grosso
}

\begin{abstract}
- RESUMO: A partir da articulação entre a História das Ideias Linguísticas (HIL) e a Análise de Discurso, este trabalho toma como questão a formulação que determina o ensino da Língua Portuguesa como língua materna, conforme materializada na Matriz de Competências e Habilidades do Ensino Médio. Dada a relevância do documento ao nortear as práticas de ensino no Brasil, busca-se refletir sobre o modo como as políticas de línguas intervêm sobre e como produz sentidos para sujeito aluno. Com as noções de língua materna e língua nacional em Payer (2006; 2007; 2009; 2016) e em Guimarães (2005), o texto propõe um percurso de leitura em que problematizamos o conceito de língua materna em funcionamento no ensino e analisamos as consequências desta posição para o saber metalinguístico do aluno no ensino médio.
\end{abstract}

- PALAVRAS-CHAVE: Discurso; Língua materna; Língua nacional; Língua Portuguesa.

- ABSTRACT: Based on the articulation between the History of Linguistic Ideas (HIL) and Discourse Analysis, this work takes as a question the formulation that determines the teaching of the Portuguese Language as the mother tongue, as materialized in the Matrix of Competences and Skills of High School. Given the relevance of the document in guiding teaching practices in Brazil, it is sought to reflect on how language policies intervene on and how it produces meanings for subject students. With the notions of mother tongue and national language in Payer (2006, 2007, 2009, 2016) and in Guimarães (2005), the text proposes a reading course in which we problematize the concept of working mother tongue in teaching and analyze the consequences of this position to the metalinguistic knowledge of the student in high school.

- KEYWORDS: Speech; Mother tongue; National language; Portuguese language.

\section{Uma questão de língua}

A partir dos pressupostos teóricos desenvolvidos sobre Língua Materna e Língua Nacional, nos estudos da linguagem, em Payer $(2006 ; 2007 ; 2009 ; 2016)$ e Guimarães (2005), propomos um percurso de leitura e análise sobre o modo como a chamada Língua

\footnotetext{
${ }^{1}$ Doutorando em Linguística pelo Programa de Pós-Graduação em Linguística da Universidade do Estado de Mato Grosso, UNEMAT. E-mail: alexalex1000@gmail.com

2 Doutora em Linguística. Professora do Programa de Pós-Graduação em Linguística PPGL/UNEMAT. E-mail: toffinho@yahoo.com.br
} 
Portuguesa, dada enquanto língua oficial do Brasil, deve ser tomada também como língua materna pelo sujeito-aluno, já que também se constitui disciplina de ensino dos currículos escolares. Inscrevemos nosso trabalho na articulação possível entre a História das Ideias Linguísticas (AUROUX,1992; ORLANDI, 2001; GUIMARÃES, 1996; 2005) e a Análise de Discurso (PÊCHEUX, 1988; PAYER, 2006), cujo entremeio possibilita-nos compreender o modo pelos quais as políticas de língua se marcam na proposta da Matriz de Referência de Competência e Habilidades do Ensino Médio, documento norteador das práticas de ensino escolar ${ }^{3}$.

Com a instituição do Enem (Exame Nacional do Ensino Médio) e, posteriormente, a aplicação do SAEB (Sistema Nacional de Avaliação da Educação Básica) advém à necessidade de elaboração e aplicação de uma matriz de competências e habilidades, cujo material recortamos para nossa leitura neste trabalho. Para entrada em nossa análise, começamos por descrever as condições de produção que tornou a Matriz de Referência uma política de ensino.

Como sabido, o ENEM foi criado em 1998 pelo Ministério da Educação com o objetivo de "[...] avaliar o desempenho do aluno ao término da escolaridade básica, para aferir o desenvolvimento de competências fundamentais ao exercício pleno da cidadania" (BRASIL, 1999, p. 5). No início, o exame foi o principal instrumento de avaliação do desempenho do Ensino Médio. Depois de quase uma década, o exame passou a ser forma de acesso ao ensino superior, funcionando como instrumento de seleção às universidades. Com esta mudança no ENEN, a avaliação de desempenho do Ensino Médio passou a ser realizada também ${ }^{4}$ pela prova SAEB. Neste contexto, aumenta a demanda para melhorar o desempenho dos estudantes do Ensino Médio de escola pública, tanto para potencializar o ingresso ao Ensino Superior, quanto para elevar a média dos resultados avaliados e, desse modo, a compilação e adoção de materiais teórico-didádicos passou a constituir uma política de alinhamento das práticas de ensino público. Assim, ao tomarmos a Matriz de Competências e Habilidades do Ensino Médio ${ }^{5}$ como nosso material de análise estamos considerando sua relação com o ENEM e com a SAEB.

Vale ressaltar que, além das escolas de ensino médio, seja pública ou privada, há um grande número de instituições que se dedicam a oferecer cursos preparatórios ao exame, e, nessa instância, esses exames são determinados pelas políticas de Estado, presentes na Matriz. Ou seja, queremos dizer que, no que tange às condições de circulação, o documento é tomado como referência em larga escala e produz força de legitimidade nas condições de produção acima descritas, portanto, o que nele se diz, regula, entre outras coisas, as ideias linguísticas para jovens estudantes no Brasil. O corpus para a leitura incide sobre a formulação que materializa a política linguística aos jovens de Ensino Médio: "Compreender e usar a língua portuguesa como língua materna, geradora de significação e integradora da organização do mundo e da própria identidade".(Grifos nossos) (BRASIL 2000, p.9)

Para a nossa reflexão, mobilizamos as noções de língua materna e língua nacional, conforme discutido por Payer $(2006 ; 2007 ; 2009 ; 2014 ; 2016)$, o que nos permitirá problematizá-las por um viés discursivo. Pela Análise de Discurso, partimos do pressuposto de que há diferenças significativas de materialidade entre língua materna e

\footnotetext{
${ }^{3}$ Com a implementação da BNCC no final de 2018, as competências e habilidades indicadas na Matriz de Competências e Habilidades do Ensino Médio foram reelaboradas e implementadas no novo Documento.

${ }^{4}$ O Saeb já avaliava o desempenho do ensino fundamental

${ }^{5}$ Disponível em http://download.inep.gov.br/educacao_basica/encceja/legistacao/2005/anexoii.pdf
} 
língua nacional. Em Payer (idem), tais noções aparecem sustentadas teoricamente de maneira a dar visibilidade a essas diferentes de materialidades no modo como as línguas funcionam em nosso país.

Payer (2006 e 2007) toma a noção de Língua Materna a partir de Rèvuz (1998), ao tratá-la como uma das dimensões da linguagem na ordem da memória, nas instâncias formadoras do sujeito, desde a mais tenra idade. Nessa perspectiva, a língua materna é fundante do sujeito. Então podemos tomar por língua materna aquela que se inscreve no sujeito através da família, em espaços informais do cotidiano, enquanto uma sua língua estruturante.

A língua nacional, para a autora, constitui-se como um elemento regulador, através do qual o Estado Nacional produz, pelo imaginário de unidade jurídica, a homogeneização na/da língua e dos sujeitos que a falam. A forma de convivência social para a constituição da cidadania tem a característica de apresentar-se pela ilusão de universalidade e igualdade. (Payer 2005).

A partir de estudos sobre os imigrantes italianos, a autora pôde compreender a não coincidência entre língua materna e língua nacional, pondo em relação o sujeito imigrante e as políticas de Estado. A princípio, a questão parecia ser a condição apenas dos sujeitos imigrantes, o que, em nosso percurso de leitura e análise, temos questionado também em relação aos sujeitos brasileiros e as políticas de Estado. Consideradas essas dimensões, a autora afirma que língua materna e língua nacional não coincidem:

A língua nacional e a língua materna não se recobrem, nem em termos empíricos, nem em termos de seu estatuto na prática delinguagem, de tal modo que se torna impossível ao sujeito transitar do estatuto de língua materna ao de língua nacional sem ter de mudar de estrutura de língua. (Payer, 2007 p.340).

As reflexões sobre língua materna e língua nacional levam Payer afirmar que funciona em um batimento, de modo tal que torna impossível ao sujeito transitar do estatuto de sua língua materna (familiar) ao de sua língua nacional (da escola) sem se mudar de materialidade linguística.

Posta a diferença entre língua materna e língua nacional, devemos nos perguntar pela historicidade de sentidos que determina a formulação "compreender e usar a língua portuguesa como língua materna, geradora de significação e integradora da organização do mundo e da própria identidade" (BRASIL, 2000 p.9) materializada na Matriz de Habilidades e Competências do Ensino Médio.

Primeiramente, vale dizer que a questão da língua no Brasil, do ponto de vista discursivo, é constitutiva do sujeito brasileiro, e, ao mesmo tempo, é considerada, pelo Estado, como condição ao exercício da cidadania. Isso diz muito de nossa história, da relação com a língua e da constituição da nação brasileira. Os trabalhos produzidos no campo da História das Ideias Linguísticas - HIL - têm permitido compreender o modo como a língua é pensada e como se dão as políticas linguísticas em nosso país.

Guimarães (2005) formula um percurso de leitura sobre as relações de línguas que constituem o espaço enunciativo do Brasil. Em A língua portuguesa no Brasil, o autor propõe quatro momentos para pensar a história dos modos de relação entre a língua e o sujeito, no Brasil.

O primeiro período abarca o início da colonização, até a saída dos holandeses em 1654 do território. Segundo autor, neste momento a língua portuguesa convive com as línguas indígenas, as línguas gerais (línguas tupi faladas pela maioria da população)e o holandês. Embora o português seja a língua oficial, neste período a língua geral (língua tupi) 
era a língua mais falada na colônia. "Eram as línguas do contato entre índios de diferentes tribos, entre índios e portugueses e seus descendentes, assim como entre portugueses e seus descendentes. A língua geral era assim uma língua franca”. (GUIMARÃES 2005 p.24)

O segundo período tem início com a saída dos holandeses e vai até a chegada da Família Real ao Brasil, em 1808. A relação linguística passa a ser entre o português, as línguas indígenas, especialmente as línguas gerais, e as línguas africanas dos escravos. Neste momento os holandeses (falantes da língua holandesa) já tinham sido expulsos do Brasil. O país recebe um número crescente de africanos trazidos na condição de escravo. Em expedição à colônia, Marquês de Pombal percebe que a língua mais falada no Brasil não era o português, assim, age para impedir o uso da língua geral. Em 1757, Pombal decreta a proibição das línguas indígenas. Assim, o português, que já era a língua oficial do Estado, passa a ser a língua mais falada no Brasil, como decorrência desse ato políticoadministrativo.

Para Guimarães (2005) o terceiro período começa com a vinda da Família Real em 1808 e termina coma Independência. Nesse período, vale evidenciar, em 1826 formulase a questão da língua nacional do Brasil no parlamento brasileiro. Vale dizer também que, com a vinda da família real, Dom João implanta no Brasil a Biblioteca Nacional e cria a imprensa, cujo gesto instrumentaliza a Língua Portuguesa à circulação e funcionamento no território nacional, conferindo ao sujeito um status social.

O quarto período apresentado por Guimarães começa em 1826, estendendo-se até a atualidade. Como características, o autor destaca que há uma transformação da língua portuguesa no Brasil: de língua do colonizador à língua da nação brasileira. Para isso, inicia-se o processo de legitimação de gramáticas e dicionários de língua portuguesa, produzidos no Brasil. Desse modo constitui-se a sobreposição do português como língua oficial e língua nacional, nessa relação, em que as línguas indígenas e as africanas ficam renegadas. As línguas indígenas e as línguas africanas funcionavam como a língua de primitivos e de escravos. Neste período, o Brasil passa a ter outras instâncias na relação intelectual entre o Brasil e outros países como França, Inglaterra e Alemanha; o francês se consolida como uma língua de cultura no Brasil, enquanto que a língua inglesa se define como língua das relações internacionais e de domínios científicos, passando a ser ensinada nas escolas como segunda língua.

Vemos em Guimarães (2005) que a Língua Portuguesa tornou-se a Língua Nacional do país a partir de um gesto de imposição política de Marquês de Pombal. Além disso, o autor nos faz perceber que as relações entre as línguas no Brasil constituíram-se por uma divisão desigual dos espaços de dizer e, a partir disso, podemos ver como essa dessimetria afeta o modo de formulação da Língua Nacional no Brasil. Notamos assim que a história sobre as línguas no Brasil determina o modo de produzir ideias sobre as línguas no Brasil.

A proposta de ensino de língua portuguesa constitui-se como um saber metalinguístico, como vemos em "Compreender e usar a língua portuguesa como língua materna, geradora de significação e integradora da organização do mundo e da própria identidade". Como os sentidos de língua materna e identidade (se) diz aí?

Para refletir sobre os sentidos em jogo mobilizamos a noção de memória discursa da Análise de Discurso. Para este campo de saber, já um pressuposto que os sentidos sempre podem ser outros, pois o sentido é relação a. Quando o sujeito toma a palavra, algo da ordem do já-dito/já-dado retorna sob a forma do pré-construído no dizer. A memória discursiva funciona justamente no movimento entre a paráfrase (o mesmo) e a polissemia (o diferente). Dizemos então, que a memória discursiva, "é o conjunto do dizível, histórica 
e linguisticamente definido" (Orlandi 1999). Ainda, a memória discursiva, que é o interdiscurso, supõe os saberes discursivos constituídos na história. No caso em análise, pelo procedimento parafrástico podemos dar visibilidade a uma rede de saber que sustenta a formulação "Compreender e usar a língua portuguesa como língua materna, geradora de significação e integradora da organização do mundo e da própria identidade" (grifos nossos). Vejamos:
A: Compreender e usar a língua portuguesa como língua materna $=>$
B:A língua Portuguesa é geradora da própria identidade.
A1: Há outras línguas no país;
A2: Outras línguas não devem ser reconhecidas como maternas;
A3: Há outras línguas no país, mas língua portuguesa deve ser compreendida como materna;
B1: Outras línguas não devem ser compreendidas como geradora da própria identidade;
AB2: Só há produção de identidade (brasileira) se compreender e usar a língua portuguesa como materna.

Os processos parafrásticos estão relacionados à memória institucionalizada (o arquivo) à estabilização, referindo-se àquilo que em todo dizer se mantém, que torna-se possível de repetição, isto é, o dizível. Desse modo, podemos dizer que a formulação de saberes metalinguísticos materializa uma contradição historicamente instalada, pois que, primeiramente, há de se observar que não há uma língua Portuguesa homogênea no Brasil. Os diferentes contatos entre os povos fizeram funcionar diferentes modos da língua, com materialidades distintas na ordem sintática, morfológica como também na ordem dos sentidos: não uma só língua portuguesa. O apagamento dessas diferenças produz o engessamento à produção de saberes linguísticos, pois toma a língua como a-histórica, anacronicamente. Se projetamos o ensino como resultado dessas determinações da Matriz, temos então um sujeito que não problematiza a sua relação com a língua, portanto, uma política de Estado que não abre espaço à compreensão discursiva da norma e da construção de saberes metalinguísticos.

Em segundo lugar, deve-se considerar que, mesmo com a política de extinção das línguas dos índios, temos ainda um número significativo de falantes nativos de mais de 200 línguas indígenas, inclusive, muitos desses nativos projetam ingressar-se em cursos superiores de ensino. Este é um ponto que, certamente, reconfigura a história das ideias linguísticas no Brasil. Em se tratando de política de ensino, no caso dos imigrantes, embora não tenham também a Língua Portuguesa como língua materna, como os indígenas, eles têm o direito de ingressar tanto no ensino médio como no ensino superior.

Enfim, ao não formular as diferenças entre língua materna e língua nacional, temos um gesto de leitura inscrito na Matriz de Competências e Habilidades do Ensino Médio que silencia o funcionamento da língua materna como a língua estruturante do sujeito. A língua materna (nos termos de Revuz, 1988 e Payer $(2006 ; 2007 ; 2009 ; 2016)$ funciona na Matriz como legitimação imaginária da Língua Portuguesa(leia-se, a da gramática e dos dicionários) como a Língua Materna. O funcionamento discursivo sobre a Língua Materna(tal qual como se formula no documento analisado), dessa forma,apaga os processos históricos de constituição do sujeito e sua relação com a(s) língua(s) que o estruturam. Assim, nega ao sujeito aluno o direito de dizer/significar-se em seus processos identitários, pois silencia as diferenças linguísticas que definem o Brasil.

Essa contradição linguística presente nas formulações da Matriz, o apagamento das diferenças e a sobre determinação de uma língua oficial sobre as demais, produz os 
diferentes modos de pensar o ensino de língua, o sujeito e a identidade linguística, na relação entre língua materna e língua nacional em território nacional brasileiro.

\section{REFERÊNCIAS}

AUROUX, S. A Revolução Tecnológica da Gramatização. Campinas: Unicamp, 1992 BRASIL. Ministério da Educação. Exame Nacional do Ensino Médio - ENEM. Documento básico. Brasília, DF: INEP, 1999.

CAVALCANTI, Rosilene da Silva de Moraes. Reflexões sobre a proposta de leitura do ENEM. 159 f. Dissertação (Mestrado em Letras) - Universidade Estadual de Maringá,Maringá, 2013

Payer, M. O. Processos de identificação sujeito/língua: ensino, língua nacional e língua materna. Campinas: Ed. Pontes, 2007.

GUIMARÃES, E. e ORLANDI, E. (Orgs.). Língua e Cidadania: O Português no Brasil. Campinas: Pontes, 1996.

SBPC, 2005. Enunciação e política de línguas no Brasil. Ciência e Cultura. São Paulo,

.A língua portuguesa no Brasil. In: Línguas do Brasil, Ciência e Cultura, Cienc. Cult. vol.57 no.2 São Paulo Apr./June 2005 (versão onlineSSN 2317-666)

Payer, M. O. Memória da Língua. Imigração e nacionalidade. São Paulo, Ed. Escuta, 2006.

Processos de identificação sujeito/língua. Ensino, língua nacional e língua materna.

Orlandi, E. (org.). Campinas: Ed. Pontes, 2007

Entre a Língua Nacional e a Língua Materna. In: Análise do discurso no Brasil. Mapeando conceitos, confrontando limites. Indursky, Freda; Ferreira, Maria Cristina Leandro. (Org.). 1 ed. São Carlos: Claraluz, 2007b, (v. 1, p. 337-346).

Dimensões Materna E Nacional Das Línguas. Anais do SILEL. Volume 1. Uberlândia: EDUFU, 2009.

Processos, modos e mecanismos da identificação entre o sujeito e a(s) língua(s). Revista Gragoatá online v. 18, Niterói, n. 34, p. 183-196, 2013

. Des-atando laços das identificações entre sujeito(s) e língua(s) In: ORLANDI,Eni P. Linguagem, sociedade, políticas. Pouso Alegre: UNIVÁS; Campinas: RG Editores, 2014.v. 1, p. 91-104.

; CELADA, Maria Teresa. Sobre sujeitos, língua(s), ensino. Notas para uma agenda. In: Subjetivação e processos de Identificação: sujeitos e línguas em práticas discursivas inflexões no ensino. Campinas, SP: Pontes Editores, 2016.

PÊCHEUX, Michel. Semântica e Discurso - uma crítica à afirmação do óbvio. Tradução de Eni Pulcinelli Orlandi et al. Campinas: Unicamp, 1988.

ORLANDI, E. (Org.). História das Ideias Linguísticas: Construção do Saber Metalinguístico e Constituição da Língua Nacional. Campinas/Cáceres: Pontes/Unemat, 2001. Editores , 2008.

Discurso e texto: formação e circulação dos sentidos. Campinas, SP:edição Pontes

.A língua Brasileira. In: Línguas do Brasil, Ciência e Cultura, Cienc. Cult. vol.57 no.2 São Paulo Apr./June 2005 (versão onlineSSN 2317-666)

Orlandi, Eni P. Discurso e texto: formação e circulação dos sentidos. Campinas, SP:edição Pontes Editores , 2008.

.A língua Brasileira. In: Línguas do Brasil, Ciência e Cultura, Cienc. Cult. vol.57 no.2 São Paulo Apr./June 2005 (versão onlineSSN 2317-666)

REVUZ, C. A Língua Estrangeira, entre o Desejo de um Outro Lugar e o Risco do Exílio. In Linguagem e identidade: elementos para uma discussão no campo aplicado. Inês SIGNORINI (org.). Campinas: Mercado de Letras; São Paulo: Fapesp, 1988

Recebido em: dezembro de 2018. 
Aprovado em: abril de 2019.

Como citar este trabalho:

ROCHA-DE-DEUS, D. A.; ALMEIDA, E. O discurso sobre língua materna e língua nacional: traço de uma colonização linguística. Traços de linguagem. V.3, n.1, p. 28 34, 2019. 